\title{
MARKETING ANALYTICS ROADMAP
}

METHODS, METRICS, ANDTOOLS

Jerry Rackley

Apress $^{\circledast}$ 


\title{
Marketing Analytics Roadmap: Methods, Metrics, and Tools
}

\author{
Copyright () 2015 by Jerry Rackley
}

This work is subject to copyright. All rights are reserved by the Publisher, whether the whole or part of the material is concerned, specifically the rights of translation, reprinting, reuse of illustrations, recitation, broadcasting, reproduction on microfilms or in any other physical way, and transmission or information storage and retrieval, electronic adaptation, computer software, or by similar or dissimilar methodology now known or hereafter developed. Exempted from this legal reservation are brief excerpts in connection with reviews or scholarly analysis or material supplied specifically for the purpose of being entered and executed on a computer system, for exclusive use by the purchaser of the work. Duplication of this publication or parts thereof is permitted only under the provisions of the Copyright Law of the Publisher's location, in its current version, and permission for use must always be obtained from Springer. Permissions for use may be obtained through RightsLink at the Copyright Clearance Center. Violations are liable to prosecution under the respective Copyright Law.

ISBN-13 (pbk): 978-1-4842-0260-9

ISBN-13 (electronic): 978-1-4842-0259-3

Trademarked names, logos, and images may appear in this book. Rather than use a trademark symbol with every occurrence of a trademarked name, logo, or image we use the names, logos, and images only in an editorial fashion and to the benefit of the trademark owner, with no intention of infringement of the trademark.

The use in this publication of trade names, trademarks, service marks, and similar terms, even if they are not identified as such, is not to be taken as an expression of opinion as to whether or not they are subject to proprietary rights.

While the advice and information in this book are believed to be true and accurate at the date of publication, neither the authors nor the editors nor the publisher can accept any legal responsibility for any errors or omissions that may be made. The publisher makes no warranty, express or implied, with respect to the material contained herein.

\author{
Managing Director: Welmoed Spahr \\ Acquisitions Editor: Susan McDermott \\ Developmental Editor: Douglas Pundick \\ Editorial Board: Steve Anglin, Mark Beckner, Gary Cornell, Louise Corrigan, James DeWolf, \\ Jonathan Gennick, Robert Hutchinson, Michelle Lowman, James Markham, \\ Susan McDermott, Matthew Moodie, Jeffrey Pepper, Douglas Pundick, Ben Renow-Clarke, \\ Gwenan Spearing, Matt Wade, Steve Weiss \\ Coordinating Editor: Rita Fernando \\ Copy Editor: Laura Poole \\ Compositor: SPi Global \\ Indexer: SPi Global \\ Cover Designer: Friedhelm Steinen-Broo
}

Distributed to the book trade worldwide by Springer Science+Business Media New York, 233 Spring Street, 6th Floor, New York, NY 10013. Phone 1-800-SPRINGER, fax (201) 348-4505, e-mail orders-ny@springer-sbm.com, or visit www.springeronline.com. Apress Media, LLC is a California LLC and the sole member (owner) is Springer Science + Business Media Finance Inc (SSBM Finance Inc). SSBM Finance Inc is a Delaware corporation.

For information on translations, please e-mail rights@apress.com, or visit wWw.apress.com.

Apress and friends of ED books may be purchased in bulk for academic, corporate, or promotional use. eBook versions and licenses are also available for most titles. For more information, reference our Special Bulk Sales-eBook Licensing web page at www. apress . com/bulk-sales.

Any source code or other supplementary materials referenced by the author in this text is available to readers at www.apress.com. For detailed information about how to locate your book's source code, go to WWw. apress. com/source-code/. 


\section{Apress Business: The Unbiased Source of Business Information}

Apress business books provide essential information and practical advice, each written for practitioners by recognized experts. Busy managers and professionals in all areas of the business world-and at all levels of technical sophistication-look to our books for the actionable ideas and tools they need to solve problems, update and enhance their professional skills, make their work lives easier, and capitalize on opportunity.

Whatever the topic on the business spectrum-entrepreneurship, finance, sales, marketing, management, regulation, information technology, among others-Apress has been praised for providing the objective information and unbiased advice you need to excel in your daily work life. Our authors have no axes to grind; they understand they have one job only-to deliver up-to-date, accurate information simply, concisely, and with deep insight that addresses the real needs of our readers.

It is increasingly hard to find information-whether in the news media, on the Internet, and now all too often in books - that is even-handed and has your best interests at heart. We therefore hope that you enjoy this book, which has been carefully crafted to meet our standards of quality and unbiased coverage.

We are always interested in your feedback or ideas for new titles. Perhaps you'd even like to write a book yourself. Whatever the case, reach out to us at editorial@apress.com and an editor will respond swiftly. Incidentally, at the back of this book, you will find a list of useful related titles. Please visit us at WWW.apress.com to sign up for newsletters and discounts on future purchases.

The Apress Business Team 

To Lisa: my wife of three decades. A man could want no finer or truer partner in life.

And,

To marketers who are searching for a better way to answer the question: "What have you done for us lately?" 



\section{Contents}

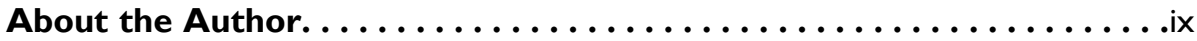

Acknowledgments...............................

Introduction. .................................iii

Chapter I: Marketing Analytics.....................

Chapter 2: The Marketing Analytics Landscape ............ 15

Chapter 3: The Impact of Marketing Analytics .............. 3 I

Chapter 4: The Marketing Analytics Process.............. 45

Chapter 5: Getting Started with Analytics................ 57

Chapter 6: Return on Investment $\ldots \ldots \ldots \ldots \ldots \ldots \ldots \ldots \ldots$ I

Chapter 7: Marketing Dashboards .................. 87

Chapter 8: Tools and Technologies ................... 103

Chapter 9: Becoming Data Driven ................... 119

Chapter 10: The Marketing Analytics Frontier ............ 133

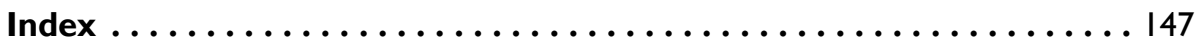





\section{About the Author}

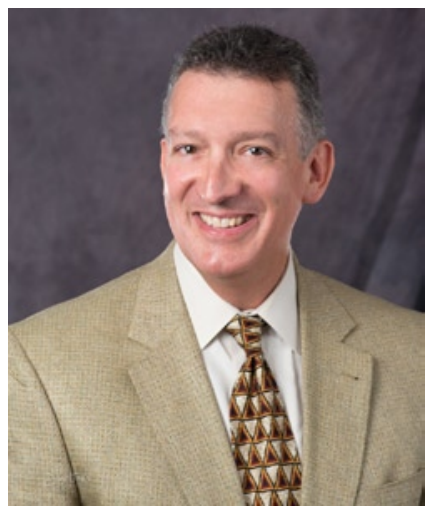

Jerry Rackley is Chief Analyst for Demand Metric, a marketing research and advisory firm, where he leads the company's research efforts. His recent studies have covered such topics as marketing analytics, social media analytics, sales and marketing alignment, digital marketing, email marketing, sales enablement, employee engagement, and content marketing. Rackley began his marketing career at IBM, and since then has held product management, marketing, and marketing communications roles in various startup, emerging, and established software companies. He is keenly interested in the culture of marketing and how companies create a competitive advantage through effective positioning. A graduate of Oklahoma State University, Rackley also serves there as an adjunct marketing faculty member in the Spears School of Business. 



\section{Acknowledgments}

I'm grateful to my Demand Metric colleagues, particularly John Follett and Jesse Hopps for their encouragement and support in the writing of this book. Likewise, to Dr. Joshua Wiener and Dr. Tom Brown in the marketing department at the Oklahoma State University Spears School of Business, who have encouraged, supported and mentored me.

There is a legion of marketing professionals who champion the cause of marketing analytics and the technology behind it: Scott Brinker, Laura Patterson, Clare Price, and Stephan Sorger, just to name a few. Their passion and enthusiasm has inspired me to put my thoughts and ideas into book form.

I owe a debt to those who have allowed me to be their marketer, both clients and employers. The experience gained from working alongside them in the marketing trenches has provided the grist for this book.

Finally, thanks to Jeff Olson, who found me, reached out to me, and convinced me to begin this book-writing adventure. Thanks to Rita, Susan, Laura, and the great team at Apress for their gracious and patient support throughout the process. 



\section{Introduction}

I entered the marketing profession quite by accident. Over 30 years ago I graduated from university with a degree in computer science, and for the 4 years I was earning that degree, I worked at the university data center. I had the academic underpinnings to develop software and a résumé that included highly relevant experience. Despite the relatively poor job market when I graduated, I had three good offers. Surprising myself, I chose the one with the lowest starting salary, at IBM, because I liked the culture and upward mobility there. IBM didn't see me as a software programmer, but instead put me in a sales and marketing branch office. I never wrote a line of code from that day forward, and I didn't regret it.

I was immediately drawn into the world of sales and marketing, and I learned everything I could from IBM, one of the best in the business at marketing its solutions. Through a series of job changes, each one pulling me deeper into the marketing profession, I learned from mentors and experience (mistakes) about how marketing works in the real world. My analytical programming background never left me. As fascinated as I was with marketing, I was also troubled by how little was known about how to connect my marketing efforts to business results. I have seen marketing get credit for business results it didn't necessarily produce, fail to get credit when it did produce results, and get blamed (fairly and unfairly) for its lack of contribution. In almost every case, judgments about marketing were based on opinion and conjecture, not data. This bothered me.

The inescapable conclusion was that the determination of marketing's success was too arbitrary, too subjective. Even if marketing was performing brilliantly, without data to prove it, the CFO could still cut marketing's budget. The CEO would question marketing's contribution. The rest of the organization could easily view marketing as a luxury, not a necessity. When reviewing other corporate functions, such as development, human resources, or sales, I noticed they each had a specific set of metrics that created clarity about how well they were getting their jobs done. This was not the case in marketing. If marketing were to get taken to court and tried for its performance, what evidence could the defense provide in favor of marketing? Very little, it seemed. 
What marketing needed was a set of metrics that moved the determination of its success out of the realm of subjective conjecture and into the world of objective fact. As a leader, I knew we needed more than the ability to say that we had churned out $X$ number of assets or managed participation in $Y$ number of trade shows and other, similarly vague attempts to connect our work to something the $\mathrm{C}$-suite cared about. These attempts at accountability left questions in everyone's minds about how well marketing was truly performing. The solution was analytics with a set of metrics that provided meaningful data about marketing's contribution, so that even for those who might disagree with marketing's methods, there was no argument about the results.

This book was born out of my past frustration and experience with how marketing manages its performance and how that performance is judged. l've written this book for the marketing organizations that have not yet started their analytics journey but know that they need to and are trying to figure out where to begin. I intend for this book to inspire marketers and marketing organizations to get moving and point them in the direction they should go. The advice contained here will provide them with a roadmap, as the title suggests, with recommendations on methods, metrics, and tools to consider on that journey. What this book will not do is provide detailed, turn-by-turn directions from start to finish of the marketing analytics journey. The reason is simple: each organization's journey must be different. The things that define the speed, vehicle, and even detours of that journey vary from company to company.

This book is not for those who have already achieved maturity with their marketing analytics process, unless perhaps they want a nostalgic tour of where they've been. That still leaves a broad audience for the direction this book provides. A study I completed in partnership with VisionEdge Marketing just as this book went to publication reveals that just one in five marketing organizations have an effective analytics process in place. For everyone elsethe 80 percent-this book will provide some encouragement and advice for starting and completing the marketing analytics journey. As the Chinese proverb attributed to Lao Tzu states: "The journey of a thousand miles begins with a single step." I hope this book helps many marketers take that first step. 